\title{
Strategies of Improving Spoken English for Learners
}

\author{
Zhanli Yang \\ Department of Pre-school Education \\ Hebei Vocational College of Foreign Languages \\ Qinhuangdao, China \\ e-mail: yz1200519751001@126.com
}

\begin{abstract}
With the rapid development of international communication and cooperation in all kinds in China, English has become one of international languages. So it is necessary to foster learners to grasp more language abilities. It is not only the main way of acquiring language information, but also the base of improving other skills. During English teaching, it is important for teachers to master the strategies of spoken English. Speaking, output of thought and information, is the base for communication, which is the most difficult item for learners comparing with the other language skills. According to the theory of self-realization, this paper offers the importance of spoken English and learning strategies of improving oral competence based on the analysis the factors that confine students' improvement of oral English.
\end{abstract}

Keywords-strategy; spoken English importance langage skill oral competence; oral English

\section{INTRODUCTION}

\section{Why do you learn English?}

People learn English for many and extremely varied reasons. Taking these reasons, as well as language acquisition needs, into consideration when planning a class or individual instruction is crucial for a successful learning experience. This is probably as important for the students as for the teacher. When a student understands his/her reasons for learning English well, he then can better plan his learning strategy. In the classroom, he/she can help the teacher identify needs and desires. If the students is learning alone, he/she can find learning materials based on a better knowledge of what his/her objectives are. Let's take a look at two of the more common reasons for learning English and what might work well for achieving learning goals.

I'd like to improve my English in order to find a better job. In this case, it's important to ask yourself the questions: Will a certificate help the chances of getting a job? Is job specific English required? Whom will I be speaking English with, native speakers or other English as a foreign language speaker? This is very important as the need for a certificate will dictate what is required learning: grammar, functional English, writing, listening, etc. If a certificate is required, the learner should focus on improving specifics points required by the examination. For example, Cambridge's First Certificate exam will require the skill of sentence transformation, the TOEFL requires the skill of understanding US test taking skills; If job specific English is required, tasks should be more real-world orientated. If possible, tasks should be based on the exact type of English required in the specific profession. For example, computer terminology for programming, presentation skills for management, etc. This is extremely important, as students who will be expected to speak English only with other non-native speakers should not have to worry as much about listening skills as those who will be expected to communicate principally with native speakers. An understanding of the culture might be important if the learner will be travelling and communicating in these countries.

I'd like to improve my English as a hobby. In this case, it is important to ask yourself the questions: How will you be using the English? Communication, Reading, Using the Internet, etc.? Do you enjoy typical task type activities? Or do you prefer real-world activities? How much do I want to improve my English? Do I want to be able to read James Joyce? This is of the utmost importance when deciding what type of activities should be pursued. If communication is most important, functional English will be preferable to grammar exercises. If reading Rolling Stone magazine is important, idiomatic language study will be required.

This is basically a question of learning style and is very important. Involved learners will always learn more in the long run than those who are bored. It's also important to remember that, if you are the teacher, imposing your learning preference on the class can, at times, deter effective learning. Understanding the desired language proficiency goal is probably one of the most important aspects of learning well. If the learner desires to communicate basic needs by travelling, focusing on the correct use of the third conditional is beside the point. On the other hand, if students strive to higher levels of grammatical understanding, teachers need to accept that role-play games might not always be the best activity.

English is not only the most useful language in the world, it also one of the easiest to learn and use. Because it has simple alphabet, easy plurals, short words etc.

\section{IMPORTANCE OF LEARNING SPOKEN ENGLISH}

In today's modern world, learning spoken English has many advantages. English is fast becoming the international language of many fields, including politics, business and education. Not only is English used between native speakers and non-native speakers, but it is also used increasingly as a common language in interactions between non-native speakers.

When you are asked to make a lecture in English, you can put it to good use. When you need to make a foreign friend, you just try a little in other ways except for English. If you are 
skilled in spoken English, you can have more access to knowledge. For example, traveling abroad to know more western customs and culture personally, making friends with foreigners because you can communicate freely with them in English, enjoying more classic western plays, films and literatures and so on.

Having a good grasp of spoken English helps you to improve your chances of employment. These days, there are many foreign companies operating from China, and many Chinese-owned companies have trade links with foreign partners. These companies require speakers of English with sufficient language skills to ensure smooth business transactions.

Spoken English also provides the chances for you to communicate socially with people from many other countries. It gives you a window into other cultures, and other perspectives of the world. It also gives you access to foreign films, TV programs, music and news.

Therefore, spoken English is an important and fundamental tool in today's global village.

\section{HOW TO IMPROVE YOUR ORAL ENGLISH}

\section{A Some effective methods to improve your spoken English}

One of the English teachers at our university got into a taxi one day, and as she talked with the driver, she noticed that he had very good spoken English, better, in fact, than that some of her students! "Where did you learn your English?" she asked. "Oh," he replied, "I never went to secondary school. I drive a taxi every day, but while I'm driving around, I listen to English radio stations. And if an English-speaking passengers gets in, I try my best to start a conversation with them. That's how I learn my English! ”

There are many things which contribute to good spoken English, but an important question for you is this: to what extent are your attitudes similar to those of the taxi driver? Are you willing to try to start a conversation with an English speaker? Or do you feel as if "the cat did get your tongue"-that whenever you try to speak in English, your tongue won't behave itself and you can hardly make a sound?

How then can you improve your spoken English? How can you try to put your resolution to improve into practice? Here we will suggest some concrete things you can do on your own (for little or no money) to improve your English-spoken English in particular.

Listen to the radio, you could get up five minutes earlier and listen to the news in English.

Try watching the news in English instead of Chinese. If you watch a movie and it has subtitles, try taping a paper over them.

Invite your English teacher to lunch! Find a friend who also wants to improve his or her English and have lunch of dinner together to speak English of course.

Check out books, records, cassette tapes, and other materials in English from your local library. Look especially for books which have lots of dialogue in them. Read plays when you go to see English films, try not to read the Chinese subtitles.

Watch for notices of English activities and join in whenever you can.

Seek out lectures in English on topics of interest to you. Try to take notes-just for your own use.

Learn the words to some popular songs (warning: don't depend on texts provided on Chinese channels or in Chinese magazines!)

Find books-on-tape in your local library. Listen while you are relaxing at home or while commuting if you have a walkman.

Watch for plays or dramatic performances given in English on campus - or get the student ticket for the public performances.

Exchange taped messages with a classmate. Record a few minutes and then ask your classmate to respond later on the same tape.

Choose a famous person whose accent you admire, and if you can get recordings of him or her, imitate the way he or she speaks.

Practice situations when you are alone, perhaps in front of a mirror. Imagine introducing yourself, disagreeing with someone's ideas, being interviewed or asking for information. If you can get someone to help, assign parts and do role-playing.

Make friends with the exchange students on our campusthey are here because they want cross-cultural communication. Communicate with them.

Take part in a play in English — start out with a small part if you feel shy.

Find a friend or two and agree to speak English at certain regular times - after a class together, at dinner every Tuesday, or riding home on the train.

Practice reading aloud-get someone to check your pronunciation and intonation, or record yourself on tape and analyze your own speech. Set goals of specific things you can work on improving ----for example, differences between words that contain "l" and " $n$ " or "w" and " $v$ ". Keep notes of words you often mispronounce and practice them.

If you have a chance to travel, take advantage of the opportunities to use English - airlines and immigration personnel, hotel and restaurant staff, fellow travelers and passengers. Visit a former English teacher either from secondary school or from a course you took at university. Teachers like to hear how their students are doing.

Everyone knows that the only really effective way to improve on language skills is to use the language. In reality, however, we know that there are many reasons why people don't want to speak in another language - they are afraid of making mistakes, they can't express their real meaning easily, they are shy, they are afraid people will laugh at them. We all feel this way some of the time, but if you really want to 
improve your spoken English, try some of the suggestions we have made here. Once you try putting some of these ideas and principles into practice, the cat will have a very hard time getting your tongue!

\section{B. How to speak more accurately}

From a learner's point of view, the problem with English is that it is too rich in constructions and vocabulary, i.e.: There are numerous words and constructions which have similar meanings. Mistakes occur when learners remember half of one construction and half of another; they end up with a hotchpotch which is at best "incorrect but understandable" and at worst "nonsense". Choose English for use or recognition purposes only English people do not use every phrase and word in the English langue. They have favorite phrases which they use time and time again. I recommend that when you are taught more than one way of saying the same thing, choose only one version to learn accurately for future use. Then store the other one vaguely in your mind for future recognition purposes only. At the same time you should avoid pitfalls. Native English speakers modify their language according to their situation, just as you would do in your own language. Unless you have constant exposure to English over many years, you cannot expect to do this. The trick therefore is to choose the best English for universal speaking purposes and to recognize other version of English, so you are not at disadvantages. By doing so, you will avoid misunderstandings and you will be able to judge the quality of another person's English.

Although a knowledge of the following is essential for understanding English (and possibly for some exams), I recommend you avoid them as much as possible when speaking in normal situation. Avoiding grammatical errors when speaking. Many students experience difficulties with the use of the present perfect, because the use of it does not correspond with a similar-looking tense in their own language. If it helps you, it is possible to avoid the present perfect altogether by using SIMPLE PAST + SPECIFIC TIME.

\section{E.G.:}

I have been to Beijing. (Time unknown) unknown)

I went to Beijing some time ago. (Exact time

I have just finished my homework. (Recent, but time unknown)

I finished my homework a short while ago. (Recent, but exact time unknown)

English is such a rich and versatile language, It is possible to say what you want to say in more than one way.

\section{How to speak more fluently}

Translation is a very difficult exercise-which is why professional interpreters make a lot of money. During a conversation, we don't really have time to translate what we understand. When you use translation to understand a foreign language, you don't develop the necessary reflexes needed to speak and understand fluently. In other words, you don't always need to translate everything to understand what is being said. Building up reflexes right from the beginning will help you later when your skills are good enough top participate in a conversation.

How do you communicate successfully when you only have basic language? It can be done! Don't rely on vocabulary and sentence structure alone. After all, what you probably want most is to be understood, not to dazzle anybody you're your command of grammar. Here are a few tips to get you communicating right off.

Relax! No one is judging you except you! Look at each communication experience as an adventure. If you are relaxed, you will pick up on small details, body language, etc. That you might miss if you are writing your hands and sweating.

Context is your friend. What is the subject, setting and situation? Use these to make intelligent guesses about what is being said. A lot of language can be eliminated when you consider context. You will feel much more comfortable and receptive if you remember that you don't have the entire Spanish language to consider at once.

Memorize clarifying questions. After you have proudly stumbled through a request for tickets at the train station, the clerk rattles off a long sentences about Vichy and Tuesday. You may be a little unclear or have only understood a portion of what was said. Rather than staring blankly, have a list of memorized clarification questions such as, "Did you say ?" and "Would you repeat that more slowly?' that you deftly use to move the communication forward. By employing these questions, you build on what you can say and understand instead of starting over with each utterance. Besides improving your communication in your school language, you improve fluently and feel confident and in charge.

Employ body language. Use gestures and facial expressions to accompany your words. Don't be afraid to be a little exaggerated. The person you are speaking to wants to understand, and will be carefully observing and listening. As you become more proficient in your second language, you will rely more on oral exchange and less on body language, but there is no shame in supporting the language you can use when you are a beginner. The alternative is to wait until you are an intermediate speaker to have meaningful interactions, and this is far too long to wait.

\section{Move your mouth}

Do not confuse pronunciation of words with their spelling! For example, "threw" and "through", although spelled differently, are pronounced the same. Also, identical letters or letter clusters in words do not always produce the same sound. For example, the "ough" in "though" and "through" represents a different sound in each word. Learn to practice what you hear, not you see.

Imagine a sound in your mind before you say it. Try to visualize the positioning of your mouth and face. Think about how you are going to make the sound.

Listen to and try to imitate the speaker. In addition to listening for specificsouds, pay attention to pauses, the intonation of the instructor's voice and patterns of emphasis. 
This can be just as important as the pronunciation of sounds.

The English language has many different dialects, and words can be pronounced differently. It is important, however, that you pronounce words clearly to ensure effective communication.

Finally, you must practice what you are learning! Remember that you are teaching your mouth a new way to move. You are building muscles that you do not use in your own language. It is like going to the gym and exercising your body. Don't forget to exercise your mouth a little bit each day.

\section{CONCLUSION}

We need more time to improve our spoken English and we should practice more. Spoken English plays an important role in English learning. And a good level of communicative competence is the final aim of English learning. How to cultivate and improve the learners' competence of spoken English has become the focal point. By using these methods, the learner can achieve his ideal goals.

\section{REFERENCE}

[1] Qiao Jian-zhong(School of Educational Science,Nanjing Normal University,Nanjing 210097,China); Theoretical Approach to the Teaching Mode of Fusing Cognition with Emotion[J];Journal of Nanjing Normal University(Social Science Edition);2006-01

[2] YUAN Ping-hua(School of Foreign Studies,Nanchang University,Nanchang 330047,China);Humanistic Psychology and Humanistic Language Teaching[J];Shandong Foreign Language Teaching Journal;2006-02

[3] Liu Runqing,; The good language learner:survey of several factors[J];Foreign Language Teaching and Research;1990-02

[4] Ma Guanghui \& Wen Qiufang;The relationship of L2 learners' linguistic variables to L2 writing ability,[J];FOREIGN LANGUAGE TEACHING AND RESEARCH;1999-04

[5] Dai Weidong; The construction of the streamline ELT system in China[J];Foreign Language Teaching and Research;2001-05

[6] Wang Chuming;Two major factors influencing L2 learning and their effect on L2 teaching[J];Foreign Language World;2001-06

[7] Yan Chuanhai, Zhang Meijuan;The interference of affective factors in foreign language teaching $[\mathrm{J}]$;Foreign Language World;2002-05 